\title{
Elementos de la confidencialidad en el ejercicio profesional del auditor*
}

\author{
Elements of confidentiality in the professional exercise of the auditor \\ Elementos de confidencialidade na prática profissional do auditor
}

\author{
Wuilliam Ruza ${ }^{\text {a }}$ \\ Universidad de Los Andes, Venezuela \\ wruza0607@gmail.com \\ ORCID: http://orcid.org/0000-0002-3826-6440 \\ Yosman Valderrama \\ Universidad de Los Andes, Venezuela \\ yosmanjose@ula.ve \\ ORCID: http://orcid.org/0000-0001-5250-7362
}

DOI: https://doi.org/10.11144/Javeriana.cc20-49.ecep

Fecha de recepción: 11 Diciembre 2018

Fecha de aprobación: 13 Mayo 2019

Fecha de publicación: 30 Junio 2019

\author{
Enderson Leal \\ Universidad de Los Andes, Venezuela
}

endersonjoseleal@gmail.com

\section{Resumen:}

La auditoría permite aumentar la confiabilidad de los estados financieros a través de la expresión de una opinión sobre si estos fueron preparados conforme al marco de referencia aplicable, para lo cual, el profesional debe actuar bajo principios éticos que garanticen la confidencialidad como relación cliente-auditor. En este artículo se describen los elementos de la confidencialidad presentes en el ejercicio profesional del auditor. Metodológicamente, el estudio se enmarcó en un enfoque cualitativo con un paradigma interpretativo, aplicando la entrevista estructurada como técnica y la guía de entrevista como instrumento de recolección de datos. La confidencialidad debe ser ejercida por el auditor bajo criterios de autonomía, respeto por los demás y confianza, apegándose a leyes y normativas que regulan la profesión, lo cual incidirá directamente en la percepción que pueda tener el entorno sobre el auditor como profesional que atiende el interés público.

Códigos JEL: M41, M42, Y80

Palabras clave: elementos de la confidencialidad, ejercicio profesional, auditoría.

\section{Abstract:}

The audit allows increasing the reliability of financial statements through the expression of an opinion on whether they were prepared in accordance with the applicable reference framework, for which the professional must act under ethical principles that guarantee confidentiality as a client-auditor relationship. Methodologically, the study was framed in a qualitative approach with an interpretive paradigm, applying the structured interview as a technique and the interview guide as an instrument for data collection. Confidentiality must be exercised by the auditor under criteria of autonomy, respect for others and trust, adhering to laws and regulations that regulate the profession, which will directly affect the perception that the environment may have on the auditor as a professional that serves the public interest.

JEL Codes: M41, M42, Y80

Keywords: Elements of confidentiality, professional practice, audit.

\section{Resumo:}

A auditoria permite aumentar a confiabilidade das demonstrações contábeis através da expressão de uma opinião sobre se foram elaboradas de acordo com o referencial aplicável, para o qual o profissional deve atuar sob princípios éticos que garantam a confidencialidade como relação cliente-auditor. Assim, a pesquisa propôs descrever os elementos de confidencialidade presentes na prática profissional do auditor. Metodologicamente, o estudo foi enquadrado em uma abordagem qualitativa com um paradigma interpretativo, aplicando a entrevista estruturada como técnica e o roteiro de entrevista como instrumento de coleta de dados. A confidencialidade deve ser exercida pelo auditor sob critérios de autonomia, respeito aos outros e confiança, aderindo às leis

Notas de autor:

\footnotetext{
a Autor de correspondencia. Correo electrónico: wruza0607@gmail.com
} 
e regulamentos que regulam a profissão, o que afetará diretamente a percepção que o ambiente pode ter sobre o auditor como profissional que serve o interesse público.

Códigos JEL: M41, M42, Y80

Palavras-chave: elementos de confidencialidade, prática profissional, auditoria.

\section{INTRODUCCIÓN}

La práctica profesional de auditoría se ha convertido en una de las actividades profesionales del contador más demandadas por los usuarios de la información financiera de las entidades, esta debe fundamentarse en las Normas Internacionales de Auditoría, las cuales establecen lineamientos y especificidades que el auditor debe atender a fin de realizar una labor enmarcada en criterios de uniformidad y universalidad en su ejercicio. Además, para desarrollar de forma correcta su trabajo, el auditor debe poseer requerimientos éticos, que son: integridad, objetividad, competencia y diligencia profesional, comportamiento profesional y confidencialidad (IESBA, 2014).

Sin embargo, algunos de estos requerimientos han sido tergiversados por profesionales que buscan el beneficio propio o el de sus clientes, ocasionando que la auditoría se vea afectada por diversos casos de escándalos financieros, que han traído como consecuencia la pérdida de la credibilidad. Tal es el caso de la confidencialidad, que si bien mantener una relación confidencial con el cliente, se vuelve fundamental, esto no debe ser motivo para que los profesionales se conviertan en cómplices de actos ilícitos perpetrados por entidades que solo buscan el enriquecimiento propio.

Campo y Tejero (2005) expresan que la confidencialidad es la relación de ayuda en la cual se da la confesión, el respeto, la seguridad, intimidad, privacidad, es decir, la protección de toda información considerada secreta. De esta manera, es fundamental para la comunidad científica esclarecer las particularidades que debe tener el criterio de confidencialidad, considerando para ello el conjunto de elementos que la integran a fin de promover un principio ético apegado a la óptica del deber y del ser.

Por este motivo, se planteó realizar esta investigación con la intencionalidad de describir los elementos de la confidencialidad presentes en el ejercicio profesional del auditor, el aporte que se realiza a la comunidad científica se centra en clarificar el principio cuestionado con base en la interpretación de un conjunto de leyes y normativas que establecen de manera implícita o explícita las acciones a tomar en caso de encontrarse con situaciones irregulares.

El trabajo de investigación está estructurado en cuatro apartados, en este orden: aspectos metodológicos que trata de los fundamentos epistemológicos que condujeron la generación del conocimiento científico; en estado del arte y avance del programa de conocimiento se expone el conjunto de postulados teóricos; en discusión de los hallazgos se presentan las manifestaciones del estudio categorizando el relato de los auditores entrevistados; y finalmente, para concluir se expone una serie de argumentos que invitan a la reflexión sobre el tema descrito.

\section{ASPECTOS METODOLÓGICOS}

El aspecto metodológico adoptado por la investigación atendió criterios de un enfoque cualitativo, el cual, no parte de supuestos derivados teóricamente, sino que busca conceptualizar sobre la realidad con base en el comportamiento, los conocimientos, las actitudes, los valores que guían el proceder de las personas estudiadas (Monje, 2011, p. 13). Siendo así, el presente estudio se fundamentó en analizar las perspectivas de los auditores relacionada con la confidencialidad de la información en el ejercicio profesional.

El enfoque epistemológico adoptado se fundamentó en la hermenéutica crítica, aplicando así, un marco referencial interpretativo para el abordaje de la investigación. Este tipo de marcos procura entender la ciencia 
de un modo que no sea ni meramente univocista ni meramente equivoquista, sino analógico. Asimismo, intenta comprenderla de un modo que no sea ni prescriptivo ni descriptivo, sino interpretativo (Ramírez et al., 2004 , p. 61.

En este contexto, aplicar un marco referencial interpretativo en el abordaje del estudio permitió a los investigadores extraer del discurso de los auditores los elementos subyacentes al principio de confidencialidad en el ejercicio profesional del auditor, los cuales fueron a su vez comparados y descritos en función de su significación con los fundamentos teóricos del trabajo.

Los sujetos informantes lo constituyeron auditores en el libre ejercicio de la profesión, que trabajan en la ciudad de Valera del estado Trujillo, Venezuela, considerando la necesidad de los investigadores de realizar una interacción con estos se acudió a un muestreo intencional el cual encuentra su fundamento en el acceso que pueda tener el investigador a los integrantes de la comunidad de estudio. En la tabla 1 se presenta de manera resumida la información académica de los auditores entrevistados, así como el código que se le asignó a cada uno de ellos para facilitar el proceso de interpretación de los hallazgos.

TABLA 1

\section{Sujetos Interactuantes}

\begin{tabular}{|c|c|}
\hline Código & Descripción \\
\hline $\begin{array}{l}\text { Auditor } 1 \\
\quad(A 1)\end{array}$ & $\begin{array}{l}\text { Mujer de } 47 \text { años, Licenciada en Contaduría Pública (Universidad del } \\
\text { Zulia), Especialista en Derecho Tributario (Universidad Santa María), } \\
\text { Especialista en Educación (Universidad Nacional Abierta), Magister en } \\
\text { Educación Superior (Universidad Rafael Maria Baralt), Magister en Gerencia } \\
\text { Financiera (Universidad Rafael María Baralt), Magister en Contaduría. } \\
\text { Mención Auditoría (Universidad Centro occidental Lisandro Alvarado), } \\
\text { Doctor en Educación (Universidad Rafael María Baralt), Asesor Tributario y } \\
\text { Auditor desde hace más de } 22 \text { años. }\end{array}$ \\
\hline $\begin{array}{l}\text { Auditor } 2 \\
\text { (A2) }\end{array}$ & $\begin{array}{l}\text { Hombre de } 60 \text { años, Licenciado en Contaduría Pública (Universidad de } \\
\text { Oriente), Especialista en Auditoría (Universidad del Zulia), Asesor } \\
\text { Tributario y Auditor desde } 1991 \text {. }\end{array}$ \\
\hline $\begin{array}{c}\text { Auditor } 3 \\
(A B)\end{array}$ & $\begin{array}{l}\text { Hombre de } 64 \text { años, Licenciado en Contaduría Pública (Universidad de Los } \\
\text { Andes), Asesor Tributario y Auditor desde } 1978 \text {. }\end{array}$ \\
\hline $\begin{array}{c}\text { Auditor } 4 \\
(A 4)\end{array}$ & $\begin{array}{l}\text { Hombre de } 43 \text { años, Licenciada en Contaduría Pública (Universidad de los } \\
\text { Andes). }\end{array}$ \\
\hline $\begin{array}{c}\text { Auditor } 5 \\
(\text { A5) }\end{array}$ & $\begin{array}{l}\text { Mujer de } 44 \text { años, Licenciada en Contaduría Pública (Universidad de los } \\
\text { Andes) }\end{array}$ \\
\hline $\begin{array}{c}\text { Auditor } 6 \\
(\text { A6) }\end{array}$ & $\begin{array}{l}\text { Hombre de años } 42 \text { años, Licenciado en Contaduría Pública (Universidad } \\
\text { de los Andes) }\end{array}$ \\
\hline
\end{tabular}

Fuente: elaboración propia.

Considerando la comunidad de estudio, la técnica de investigación aplicada fue la entrevista y como instrumento de recolección de datos se empleó una guía prediseñada contentiva de tres preguntas formuladas al entrevistado. En efecto, la presente investigación acudió a un proceso de revisión del instrumento a través de la validez de contenido realizado por el juicio de tres expertos, quienes verificaron y analizaron el contenido y la correlación entre los ítems de las sub categorías, así como el contexto teórico que sustenta el trabajo, determinaron la precisión y calidad de las preguntas planteadas.

Para analizar e interpretar los datos de esta investigación se acudió a la técnica de triangulación de datos y la categorización post entrevista, el cual contribuyó con los investigadores y facilitó la extracción de lo expresado por los auditores en las entrevistas para su contrastación con lo establecido en la teoría con la finalidad de exponer las conclusiones.

Luego de que los expertos aprobaron el instrumento y lo aplicaron se realizó el proceso de categorización. Se identificaron las categorías emergentes en la investigación, lo que permitió la comprensión interpretación, reconstrucción y reflexión de las experiencias de los informantes sobre el tema investigado. 
Finalmente, los investigadores aplicaron la categorización a partir de la consideración de los aspectos resaltantes de la entrevista con la finalidad de obtener una comprensión acerca de las perspectivas de los sujetos interactuantes de cada una de las sub categorías.

\section{ESTADO DEL ARTE Y AVANCE DEL PROGRAMA DE CONOCIMIENTO}

El Manual de Ética Médica emitido por la Asociación Médica Mundial (AMM, (2015) expresa que la confidencialidad se basa en tres elementos fundamentales: la autonomía, el respeto por los demás y la confianza, los cuales respectivamente son tratados por las Normas Internacionales de Auditoría y el Manual del Código de Ética para Profesionales de la Contabilidad (IESBA, 2014) como: independencia, respeto y confiabilidad.

\section{Autonomía o independencia}

La palabra autonomía proviene del griego y sus componentes léxicos son: autos $=$ por sí mismo; nomos $=$ regla; y el sufijo, Ía = acción, cualidad. (RAE, 2014). Así, la autonomía es la acción de regirse por sí mismo, de ser autónomo y tomar decisiones propias. Al respecto, el auditor debe respetar el principio de confidencialidad obtenida de la relación profesional y en efecto, no puede revelar la información sin autorización adecuada, por lo tanto, debe cumplir con la autonomía como elemento fundamental (IESBA, 2014).

La autonomía permite al auditor mantener la confidencialidad de la información en la auditoría, es decir, la información financiera de un cliente le pertenece solo a él y a su entidad, las operaciones mercantilesfinancieras, las políticas de control, procedimientos que el realice no debe ser comunicado a terceros, sin autorización previa.

Por tanto, la autonomía que la sociedad otorga a las profesiones justifica que ésta exija a los profesionales el desarrollo de una labor responsable, enmarcada en contribuir con el bienestar social y el desarrollo de una actividad con sentido ético frente a su condición de ser humano en sociedad (Barrainkua, 2012).

La autonomía es tratada en las Normas Internacionales de Auditoría como independencia, la cual requiere del profesional contable una actitud mental que le permita concluir y expresar su opinión alejada de conflictos de interés e influencia indebida de terceros, el apartado 14 de la NIA 200 (IAASB, 2016) establece que "el auditor está sujeto a los requerimientos de ética aplicables relativos a los encargos de auditoría de estados financieros, incluidos los relativos a la independencia”.

El requerimiento de la NIA 200 hace necesario mantener una actitud independiente, la cual de conformidad con el apartado A16 de la NIA 200 "salvaguarda la capacidad del auditor para formarse una opinión de auditoría no afectada por influencias que pudieran comprometer dicha opinión” (IAASB, 2016).

Aunado a esto, la NIA 260 en el apartado A30 literales a y b tipifica las posibles amenazas que ponen en riesgo la independencia del auditor o de la firma de auditores, estas pueden clasificarse como "amenazas de interés propio, de autorrevisión, de abogacía, de familiaridad y de intimidación; y las salvaguardas establecidas por la profesión o por las disposiciones legales o reglamentarias, las salvaguardas existentes dentro de la propia entidad".

En el caso que existan amenazas a la independencia la NIA 220 en el apartado 11 literal c establece que el profesional "adoptará las medidas adecuadas para eliminar dichas amenazas o para reducirlas a un nivel aceptable mediante la aplicación de salvaguardas o, si se considera adecuado, para renunciar al encargo de auditoría si las disposiciones legales o reglamentarias así lo permiten" (IAASB, 2016).

Por otra parte, la Norma Internacional de Control de Calidad (NICC- 1) en el apartado 20 establece que "la firma de auditoría establecerá políticas y procedimientos diseñados para proporcionarle una seguridad 
razonable de que tanto ella misma como su personal mantienen la independencia cuando lo exigen los requerimientos de ética aplicables" (IAASB, 2016, p. 42.

Las normas que rigen el trabajo de auditoría expresan la importancia que tiene la independencia para que el desarrollo de ésta se realice de manera correcta, dejando a un lado todos aquellos aspectos tanto internos como externos que puedan afectar el objetivo de la auditoría. Es decir, la independencia es una cualidad de la persona de realizar su ejercicio profesional sin dejarse influenciar por hechos externos, o sentir restricciones o limitantes relacionadas con sus sentimientos o relaciones con sus pares (Viloria, 2009, p. 116).

En el contexto del auditor la autonomía se fundamenta en desarrollar un pensamiento íntegro, objetivo y escéptico que le permita fortalecer su opinión frente a terceros atendiendo a la satisfacción del interés público. Por tanto, la autonomía está asociada con la independencia mental del auditor, por lo cual, el profesional contable deberá desarrollar un pensamiento objetivo e imparcial, que le permita sustentar su trabajo profesional sin responder a intereses propios o particulares sino que, por el contrario, le permitan responder a las demandas de la sociedad, frente a la atención del interés general y colectivo.

\section{Respeto por los demás}

La palabra respeto proviene del latín respectus y significa "atención" o "consideración" y está "relacionado con la veneración o el acatamiento que se hace a alguien. Incluye miramiento, acatamiento y deferencia” (RAE, 2014). De este modo, el respeto representa el sentimiento, estima o consideración que se tiene hacia algo o alguien.

El respeto es el reconocimiento del valor propio, de los derechos de los individuos y de la sociedad. El respeto, es un sentimiento fundamental que posibilita la adquisición de nociones morales. (Piaget, 1960, p. 160). "La confidencialidad también es importante porque los seres humanos merecen respeto. Una forma importante de demostrarles respeto es mantener su privacidad" (AMM, 2015, p. 51).

En este contexto, el respeto es la dignidad personal que se propone reconocer en los usuarios personas con dignidad, inteligencia, libres y con destino transcendente. Además, expresa que "en un profesional ético, el usuario encuentra siempre protección contra daños nacidos del ejercicio profesional inadecuado y encuentra protección a su intimidad y a su dignidad personal" (Álvarez, 2002, p. 154).

El Manual del Código de Ética para Profesionales de la Contabilidad (IESBA, 2014) en la sección 100 literal (d), instituye que el auditor debe respetar el principio de confidencialidad obtenida de la relación profesional, de este modo, el profesional contable garantiza su secreto profesional amparado en atender a la no divulgación de la información que le es dada, considerando su posición privilegiada ante la información y sin querer sacar provecho de esta. La sección 140.1 literal b establece que el profesional contable manifiesta su respeto a través de la abstención de:

(a) divulgar, fuera de la firma o de la entidad para la que trabaja, información confidencial obtenida como resultado de relaciones profesionales y empresariales, salvo que medie autorización adecuada y específica o que exista un derecho o deber legal o profesional para su revelación, y

(b) utilizar información confidencial obtenida como resultado de relaciones profesionales y empresariales en beneficio propio o de terceros (p. 19). Adicionalmente, el referido código expresa que,

el auditor en su actuación, durante y posterior a la auditoría deberá evitar cualquier tipo de condicionantes personalizados y actuar en todos los casos con similar diligencia. [Y] su actuación deberá mantener una igualdad de trato profesional con la totalidad de personas con las que en virtud de su trabajo tenga que relacionarse. (IESBA, 2014)

Sintetizando, el respeto dentro de la confidencialidad para la auditoría es un factor fundamental que unido a la autonomía, representa elementos interrelacionados; el cliente, al presentarle los informes financieros para que el auditor exprese una opinión sobre la veracidad de la misma, exige que el profesional lo haga con mayor responsabilidad respetando el carácter confidencial de la información. 


\section{Confianza o confiabilidad}

La palabra confianza proviene del griego y sus componentes léxicos son el prefijo con: todo, junto; la raíz fi: del verbo fiar y el sufijo anza: cualidad. (RAE, 2014). En otras palabras, la confianza se asocia con la cualidad que muestra el sujeto que tiene en sí mismo, total seguridad o pone ante otro su credibilidad total.

La importancia y utilidad de la auditoría para garantizar la estabilidad financiera exige como requisito imprescindible la confianza en dicha función y en los profesionales que la desarrollan. Los auditores deben demostrar una conducta ética en el desarrollo de su profesión para cumplir con las expectativas de aquellos que confían en sus informes para tomar decisiones (Barrainkua, 2012). En este sentido, los códigos de conducta fijan las líneas generales de actuación y las obligaciones éticas de sus miembros con el fin de mantener la confianza del público en su labor y proteger el buen nombre de la profesión.

El auditor tiene como finalidad verificar la razonabilidad y confiabilidad de la información financiera que presentan las empresas, dando certeza y confianza a la información auditada. (Melgarejo, 2006, p. 1). Por ello la confianza debe ser fundamental en el desarrollo del trabajo ya que la misma garantiza la razonabilidad y transparencia de la auditoría. Al respecto, el auditor es la persona que recibe información en confianza porque quien la entrega sabe qué hará un uso cuidadoso (Slosse, 2002, p. 56).

La confianza es un concepto subjetivo que tiene estrecha relación con la seguridad, en efecto cuando algo parece seguro, suele pensarse que es confiable. (Gil y Rondón, 2016, p. 4). Además, exponen que los Contadores Públicos tienen la facultad de dar fe pública de los hechos y documentos, por lo tanto, generan confianza pública. El Contador Público es depositario de la confianza pública, da fe pública cuando con su firma y número de tarjeta profesional suscribe un documento en que certifique sobre determinados hechos económicos. (Álvarez, 2002, p. 161), por ello el profesional contable debe estar debidamente registrado en una institución que legitime y regule todas las actividades que realice.

Los usuarios de los servicios de los contadores profesionales deben ser capaces de sentir confianza de que existe una estructura conceptual de ética profesional que gobierne la prestación de esos servicios. (Álvarez, 2002, p. 161).

En este contexto, la confianza es la seguridad que alguien tiene en otra persona, es la piedra angular en la relación de auditor-cliente. El éxito de esta relación es proteger la confiabilidad que el cliente ha depositado en el profesional, por esta razón, el cliente deberá cumplir ciertas obligaciones para lograr el éxito y el auditor proporcionar la seguridad suficiente para llevarlo a cabo. Aunque no olvidándose que el objetivo del auditor es servir al interés público.

\section{DISCUSIÓN DE LOS HALLAZGOS}

Los elementos de la confidencialidad constituyen aquellos aspectos que el auditor debe poseer en su personalidad al momento de desarrollarse en el ejercicio profesional, con el propósito, de obtener resultados de valor en la auditoría, entre ellos se encuentran, la autonomía o independencia, respeto por los demás y la confianza o confiabilidad, todos garantizan la transparencia, objetividad, calidad e integridad del servicio profesional, los hallazgos de la investigación enmarcados en estos elementos se presenta a continuación.

\section{Autonomía o independencia}

Para los investigadores, la autonomía es la acción que permite al auditor tomar decisiones basadas en la experiencia, conocimiento y juicio profesional, abordada a través de las Normas Internacionales de Auditoría (IAASB 2016), Manual del Código de Ética para Profesionales de Contabilidad (IESBA 2014), Barrainkua (2012) y Viloria (2009). 
Las Normas Internacionales de Auditoría (IAASB 2016 exponen que el auditor debe mantener una actitud independiente durante su profesión, desarrollada a través del conocimiento y experiencia para fomentar un juicio profesional autónomo a fin de tomar decisiones firmes y acertadas, alejándose de la influencia de factores que podrían afectar su conducta en el transcurso de la auditoría, todo ello en concordancia con lo establecido en el Manual del Código de Ética para Profesionales de Contabilidad (IESBA, 2014.

La Autonomía como subcategoría de investigación se abordó en los entrevistados con la interrogante ¿cuáles son los aspectos que como auditor considera para mantener la autonomía en el ejercicio profesional? En la tabla 2 se refleja el extracto de las respuestas de cada uno de los sujetos interactuantes a quienes se le aplicó el instrumento.

TABLA 2

Aspectos considerados para mantener la autonomía en el ejercicio profesional

\begin{tabular}{|c|c|}
\hline $\begin{array}{l}\text { Código de } \\
\text { análisis }\end{array}$ & Extracto de los hallazgos \\
\hline A1 & $\begin{array}{l}\text { Para yo tener autonomía, no debo tener ninguna relación, ningún vínculo } \\
\text { con alguien de la entidad que uno va a auditar. Por eso dice el Código de } \\
\text { Ética que hasta el cuarto grado de consanguinidad no podemos hacer } \\
\text { ningún trabajo, porque eso nos corta la autonomía. }\end{array}$ \\
\hline $\mathrm{A} 2$ & $\begin{array}{l}\text { En el ejercicio profesional todos somos autónomos, mientras } \\
\text { mantengamos el criterio, la objetividad. No tenemos autonomia cuando } \\
\text { nos sometemos a realizar un trabajo bajo relación de dependencia o } \\
\text { hacerlo desde el punto de vista como no los exija o no los quiera exigir } \\
\text { que se le haga el cliente. El auditor es autónomo cuando es libre en la } \\
\text { revisión, de expresar o informar todos los hallazgos y recomendaciones } \\
\text { que pudiéramos dar, allí se mantiene autonomía. }\end{array}$ \\
\hline A3 & $\begin{array}{l}\text { Los aspectos son que la información deber ser manejada con mucho } \\
\text { profesionalismo y con mucha seriedad. }\end{array}$ \\
\hline A4 & $\begin{array}{l}\text { Yo pienso que el aspecto fundamental es el tema de la contratación, el } \\
\text { tema de la ética y entender el alcance básico de hasta dónde vas a llegar } \\
\text { con la auditoría. Si tú tienes claro esos tres aspectos yo creo que estás } \\
\text { muy cerca de mantenerte autónomo. }\end{array}$ \\
\hline A5 & $\begin{array}{l}\text { Yo creo que la manera como esté uno formado, la experiencia y los } \\
\text { conocimientos que tengas de la normatividad, eso te permitirá ser lo } \\
\text { suficientemente autónomo. }\end{array}$ \\
\hline A6 & $\begin{array}{l}\text { Cuando uno va auditar, lo principal es la planificación, ¿Qué es lo que se } \\
\text { va hacer? Ahí demuestro cual es mi autonomia, sé hasta dónde llegar } \\
\text { porque hay información en las empresas que por más que yo sea } \\
\text { autónomo y decido mi criterio, no puedo violentar las normas de la } \\
\text { empresa. }\end{array}$ \\
\hline
\end{tabular}

Fuente: instrumento aplicado por los investigadores, 2018.

La tabla 2 evidencia una variedad de opiniones sobre los aspectos considerados para mantener la autonomía en el ejercicio profesional, dentro de los cuales los auditores consideran que:

1. la contratación debe ser fundamental para que un trabajo de auditoría se realice de manera independiente, ya que en este se establece el alcance;

2. el trabajo profesional debe evitar cualquier tipo de relación existente entre auditor-cliente, resaltando los vínculos de consanguinidad;

3. la labor de auditoría debe fundamentarse en la formación profesional obtenida a través de la experiencia y el conocimiento para crear una independencia sólida; y finalmente,

4. el auditor debe manejar la información con profesionalismo y seriedad manteniendo la objetividad, el criterio propio y la planificación. 
Estos hallazgos de investigación, al ser contrastados con los fundamentos teóricos y normativos establecidos sobre la profesión contable permitieron determinar una diversidad de puntos.

El primer punto, al considerar lo expuesto por el auditor A1 quien expresó que "no se debe tener ninguna relación, ningún vínculo con alguien de la entidad" evidencia un cumplimiento de lo establecido la sección 280.1 del Manual del Código de Ética para Profesionales de Contabilidad el cual señala que "una relación familiar o una relación estrecha, personal o empresarial, pueden generar una amenaza de familiaridad en relación con la objetividad" (IESBA 2014). Asimismo, la independencia se presenta "como una cualidad de la persona de realizar su ejercicio profesional sin dejarse influenciar por hechos externos, o sentir restricciones o limitantes relacionadas con sus sentimientos o relaciones con sus pares" (Viloria, 2009, p. 116).

Significa entonces, que los auditores consideran fundamental mantener una relación entre auditor-cliente estrictamente profesional, de modo tal, que la objetividad y transparencia de la auditoría no se vea afectada por vínculos considerados en la normativa como amenazas a las cuales está expuesto el auditor.

Parafraseando las ideas expuestas por el auditor A2 para mantener la autonomía se debe aplicar un criterio propio con objetividad, lo cual permitirá aumentar "la capacidad de un profesional de llegar a conclusiones correctas respecto a los asuntos que se encomiendan" (Gil y Rondón, 2016, p. 29). Además, para el profesional A3 la información deber ser manejada con profesionalismo y seriedad, de conformidad con lo establecido en el apartado A16 de la NIA 200, instituyendo que la independencia "salvaguarda la capacidad del auditor para formarse una opinión de auditoría no afectada por influencias que pudieran comprometer dicha opinión" (IAASB, 2016).

Con base en los planteamientos anteriores, los auditores entrevistados mantienen en su accionar un comportamiento autónomo con miras a desempeñar su ejercicio de manera objetiva, aplicando su criterio con base en conocimientos y experiencias adquiridas, generando de esta manera, mayor seguridad y confianza.

Adicionalmente, para mantener una actitud autónoma en el proceso de auditoría es necesario trabajar dentro del marco de la legalidad, lo cual resultó fundamental para los auditores A4 y A6 quienes en su discurso expusieron que la autonomía depende del alcance que se establezca en el contrato, puesto que allí se determina hasta qué punto la auditoría puede llegar y hasta donde no. En este sentido, el apartado 9 de la NIA 210 establece "que el auditor acordará los términos del encargo de auditoría con la dirección o con los responsables del gobierno de entidad, según corresponda" (IAASB, 2016).

Aunado a esto, el apartado 10 de la referida normativa tipifica que los términos del encargo de auditoría acordados se harán constar en una carta de compromiso e incluirá: a) el objetivo y el alcance de la auditoría de los estados financieros; b) las responsabilidades del auditor; y c) las responsabilidades de la dirección.

En este sentido, los auditores entrevistados reconocen el rol que desempeña el contrato dentro del encargo de auditoría, haciéndolo indispensable para iniciar la revisión y establecimiento de los objetivos y alcance de la misma. No obstante, los entrevistados no consideran que este mecanismo legal pueda reducir la exposición a riesgos frente a la función de la autonomía, derivado de la valoración de las amenazas y limitaciones que le impidan ejercer su independencia y alcanzar sus objetivos, que lo puede apartar del ejercicio pleno de la auditoría, afectando su transparencia e integridad.

$\mathrm{Al}$ respecto, el apartado 7 de la NIA 210 requiere que si la "dirección incluye en la propuesta del encargo la imposición de una limitación al alcance del trabajo del auditor que este considere que tendrá que denegar la opinión sobre los estados financieros, el auditor no aceptará dicho encargo con limitaciones" (IAASB, 2016). Siendo así, los auditores deben considerar que el contrato de auditoría no debe establecer restricciones a una determinada información o imposiciones de limitaciones, considerando lo establecido en el apartado 6 literal (b) de la NIA 210 la cual expresa que la dirección "deberá proporcionar al auditor acceso a toda información de la que tenga conocimiento la misma”.

El segundo punto es develado por el auditor A5 quien expresa que para mantener una mentalidad autónoma se debe poseer conocimientos suficientes y adecuados en las leyes, esto cobra un valor fundamental en la autonomía, ya que basar las opiniones estructuradas bajo un marco legal y normativo brinda firmeza y 
estabilidad a la hora de la emisión de las mismas, para ello, la NIA 250 establece "la responsabilidad que tiene el auditor de considerar las disposiciones legales o reglamentarias en la auditoría de estados financieros" (IAASB, 2016.

Asimismo, el conocimiento aplicado por los auditores entrevistados en su actividad profesional contribuye con la detección de incorrecciones materiales en los estados financieros o la reafirmación de que los mismos fueron elaborados conforme a todo lo importante, ajustándose de esta manera al requerimiento establecido en el apartado 14 de la NIA 250, que implanta como obligación para el auditor la aplicación de "procedimientos de auditoría con el fin de ayudar a identificar casos de incumplimiento de otras disposiciones legales y reglamentarias, que puedan tener un efecto material sobre los estados financieros" (IAASB, 2016.

Por los hallazgos, podría afirmarse que adicional a lo señalado por los auditores entrevistados, la autonomía debe estructurarse bajo estándares escépticos, que le permitan al auditor tomar una actitud cuestionante de la información que se le presenta, aplicando para ello lo establecido en el apartado 13 literal (k, de la NIA 200, que conceptualiza el escepticismo como una "actitud que implica una mentalidad inquisitiva, una especial atención a las circunstancias que puedan ser indicativas de posibles incorrecciones debidas a errores o fraudes, y una valoración crítica de la evidencia de auditoría" (IAASB, 2016. Lo que permitirá fomentar la autonomía desde la perspectiva del cuestionamiento de la información en todo el proceso de la revisión de los estados financieros.

\section{Respeto por los demás}

Otro elemento de la confidencialidad es el respeto por los demás, un valor imprescindible en la relación auditor-cliente, que fomenta el correcto comportamiento que el profesional debe mostrar ante sus usuarios con respecto a la información que le fue suministrada. Las concepciones teóricas de este elemento se obtuvieron del Manual del Código de Ética para Profesionales de Contabilidad (IESBA 2014.

El respeto es un valor fundamental en la relación auditor-cliente, debido a que es el elemento que permite al profesional brindar mayor comodidad para que el cliente se sienta seguro al momento de suministrar la información solicitada. Sin embargo, en la actualidad se han evidenciado numerosos casos en los que el auditor ha sacado provecho de esas relaciones para beneficio propio o de terceros. Por esta razón, se acudió a preguntarles a los auditores cómo describen ellos sus acciones para evitar sacar ventaja de la información. En la tabla 3 se presentan las respuestas obtenidas por los entrevistados. 
TABLA 3

Acciones que los auditores realizan para evitar sacar ventaja de la información obtenida en el proceso de auditoría

\begin{tabular}{|c|c|}
\hline $\begin{array}{l}\text { Código de } \\
\text { análisis }\end{array}$ & Extracto de los hallazgos \\
\hline A1 & $\begin{array}{l}\text { No sacamos ventaja de nada, simplemente la experiencia nos va dando la } \\
\text { oportunidad de ir evaluando los procesos. }\end{array}$ \\
\hline $\mathrm{A} 2$ & $\begin{array}{l}\text { Estableciendo los honorarios, ser honesto consigo mismo, con la profesión } \\
\text { y para quien lo contrato. Evitar desde todo el punto de vista de } \\
\text { aprovecharte, porque si no estarias siendo corrupto o cómplice de otro. }\end{array}$ \\
\hline A3 & $\begin{array}{l}\text { Yo creo que aquí esto de sacar ventaja tiene que ver mucho con el } \\
\text { aprovechamiento indebido, pienso que como auditor te ubican para un } \\
\text { determinado trabajo es porque precisamente tú generas confianza, esa } \\
\text { seriedad profesional. Si tú careces de esas tres cualidades: confianza, ética } \\
\text { y responsabilidad nadie te va ubicar a ti ni para interno ni para externo. }\end{array}$ \\
\hline A4 & $\begin{array}{l}\text { En principio no es ético de que te valgas de la información que manejas } \\
\text { para sacar ventaja, eso en principio. No veo eso de sacar ventaja por el } \\
\text { tema ético y porque dentro del mismo alcance de la revisión tú vas a tener } \\
\text { que hacerlo. }\end{array}$ \\
\hline A5 & $\begin{array}{l}\text { En lo particular pienso que debemos ser íntegros en nuestro trabajo, } \\
\text { debemos apegarnos a nuestros valores. Mantener la privacidad del cliente } \\
\text { es fundamental. }\end{array}$ \\
\hline A6 & $\begin{array}{l}\text { No es que el auditor saque ventaja, es que tiene que ser perspicaz, audaz; } \\
\text { o no es que te saca ventaja es que tiene una ventaja ya implicita. Toda } \\
\text { acción del auditor debe estar planteada como una acción, vamos a decirlo } \\
\text { así con pericia por supuesto, pero además tiene que ser perspicaz. Es } \\
\text { indispensable que la acción de la auditoría se realice con audacia. }\end{array}$ \\
\hline
\end{tabular}

Fuente: Instrumento aplicado por los investigadores, 2018.

Las opiniones brindadas por los auditores A2, A3 y A4 consideran que se deben aplicar acciones honestas consigo mismo, con la profesión y con el cliente, particularmente el auditor A4 expresó que "en principio no es ético que te valgas de la información que manejas para sacar ventaja". En concordancia con lo establecido en la sección 150.2 del Manual del Código de Ética para Profesionales de la Contabilidad (IESBA, 2014), el cual instituye que "los profesionales de la contabilidad serán honestos y sinceros".

Los argumentos de los auditores entrevistados se ajustan teóricamente a lo expresado por Álvarez (2002) quien expresa que "la honradez profesional debe ser el resultado de la función social de la profesión como trabajo dirigido al bien común y que impide sustraer el beneficio personal al bien común". Lo que evidencia que los sujetos interactuantes son profesionales que en su labor atienden el bienestar de su cliente, desarrollando actitudes honestas y transparentes hacia estos.

Aunado a esto, el auditor A2 manifestó que su labor evita realizar acciones que conlleven a convertirlo en un profesional corrupto o cómplice de actividades ilícitas de sus clientes. Apegándose así a las disposiciones legislativas que colocan al profesional contable y auditores como sujetos políticamente obligados a prevenir la Legitimación de Capitales, tal es el caso de los preceptos venezolanos establecidos por la Ley Orgánica contra la Delincuencia Organizada y financiamiento al Terrorismo de 2012.

Todo esto de conformidad con lo establecido en el apartado A55 de la NIA 200 en la cual se requiere que "en la realización de una auditoría, además de las NIA, el auditor puede tener que cumplir requerimientos legales o reglamentarios" (IAASB, 2016). De este modo, es indispensable que el profesional contable posea conocimientos generales y suficientes que abarquen leyes y normativas aplicables a la jurisdicción donde realiza su trabajo.

De los hallazgos de la investigación se infiere que en el ámbito venezolano, los auditores en su labor se ajustan a diversas disposiciones legales que establecen la obligatoriedad del auditor de velar por la seguridad social económica y financiera del país, evitando delitos que sean cometidos por sus clientes. En la Matriz de 
análisis se presenta un extracto de las principales leyes nacionales que establecen responsabilidad del auditor frente la prevención de delitos económicos, así como las diferentes sanciones a las cuales está expuesto en caso de ser partícipe de hechos delictivos.

TABLA 4

Responsabilidades del auditor para contrarrestar actos ilícitos

\begin{tabular}{|c|c|}
\hline Normativa & Descripción \\
\hline $\begin{array}{l}\text { Constitución de } \\
\text { la República } \\
\text { Bolivariana de } \\
\text { Venezuela } \\
\text { (1999) }\end{array}$ & $\begin{array}{l}\text { Disposición Transitoria quinta: } \\
\text { Numeral 5: La ampliación de las penas contra asesores(a), } \\
\text { abogados(a), auditores(a) que actuen en complicidad para cometer } \\
\text { delitos tributarios, incluyendo periodos de inhabilitación para el } \\
\text { ejercicio de su profesión. }\end{array}$ \\
\hline $\begin{array}{l}\text { Código Orgánico } \\
\text { Tributario } \\
\text { (2014) }\end{array}$ & $\begin{array}{l}\text { Artículo 89: Se les aplicará la inhabilitación para el ejercicio de la } \\
\text { profesión por un término igual a la pena impuesta, a los } \\
\text { profesionales y técnicos que con motivo del ejercicio de su profesión } \\
\text { o actividad participen, apoyen, auxilien o cooperen en la comisión } \\
\text { del ilícito de defraudación tributaria. }\end{array}$ \\
\hline \multirow{4}{*}{$\begin{array}{l}\text { Ley Orgánica } \\
\text { contra la } \\
\text { delincuencia } \\
\text { organizada y } \\
\text { financiamiento } \\
\text { al terrorismo } \\
(2012)\end{array}$} & $\begin{array}{l}\text { Artículo 9: Consideran sujetos obligados de conformidad con esta } \\
\text { ley los siguientes; específicamente numeral 9: los abogados, } \\
\text { abogadas, administradores, administradoras, economistas y } \\
\text { contadores o contadoras en el libre ejercicio de su profesión. }\end{array}$ \\
\hline & $\begin{array}{l}\text { Artículo 12: Los sujetos obligados por esta Ley deberán establecer } \\
\text { mecanismos que permitan detectar cualquier transacción inusual o } \\
\text { sospechosa, aun cuando éstas tengan una justificación económica } \\
\text { aparente o visible. }\end{array}$ \\
\hline & $\begin{array}{l}\text { Artículo 13: Los sujetos obligados deben prestar especial atención a } \\
\text { cualquier transacción o grupo de transacciones independientemente } \\
\text { de su cuantia y naturaleza, cuando se sospeche que los fondos, } \\
\text { capitales o bienes provienen o están vinculados, o podrian ser } \\
\text { utilizados para cometer delitos de legitimación de capitales, acto } \\
\text { terrorista o financiamiento al terrorismo o cualquier otro delito de } \\
\text { delincuencia organizada. } \\
\text { En los casos anteriores los sujetos obligados deberán informar de } \\
\text { manera expedita a través de los reportes de actividades sospechosas } \\
\text { a la Unidad Nacional de Inteligencia Financiera. }\end{array}$ \\
\hline & $\begin{array}{l}\text { Artículo 14. Los sujetos obligados y empleados o empleadas de éstos } \\
\text { y éstas, no revelarán al cliente, usuario o usuaria, ni a terceros, que } \\
\text { se ha reportado información a la Unidad Nacional de Inteligencia } \\
\text { Financiera u otras autoridades competentes, asi como tampoco que } \\
\text { se está examinando alguna operación sospechosa vinculada con } \\
\text { dicha información. Tampoco podrán revelar que la han } \\
\text { suministrado a otras autoridades competentes. }\end{array}$ \\
\hline
\end{tabular}

Fuente: elaboración propia.

Los hallazgos de la investigación demuestran que los auditores entrevistados fundamentan su actividad profesional en el cumplimiento legislativo, y por tanto, se ajustan a las disposiciones emanadas por el Estado venezolano, en cuanto a la prevención de participar o amparar con su actividad hechos delictivos. Podría afirmarse entonces, que los profesionales en actividad de auditoría conocen las implicaciones jurídicas que conlleva ser cómplice de clientes que realizan actos ilícitos, y por tanto, evitan formar parte de operaciones delictivas que necesitan su colaboración para dar apariencia legal.

No obstante, el discurso de los entrevistados aun cuando evidencia un acatamiento legal en cuanto a salvaguardar su responsabilidad frente a situaciones sospechosas, estos no manifiestan interés de informar o revelar hechos delictivos o condiciones sospechosas ante órganos jurídicos establecidos por la normativa para ajustarse a las disposiciones legislativas establecidas en la (Ley orgánica contra la delincuencia organizada y financiamiento al terrorismo, 2012). 
Interpretando el discurso de los entrevistados podría afirmarse que los auditores evitan acciones enfocadas en sacar ventaja de la información que se le suministra, trabajando bajo conceptos de integridad. Tal hecho queda evidenciado en lo expuesto por auditor A5 quien opina que el respeto por los demás se manifiesta a través de una actitud integra en el trabajo, apegándose a los valores y manteniendo la privacidad del cliente para evitar todo tipo acción que genere el aprovechamiento de la información para actos no gratos.

De tal modo, que los auditores se ajustan a lo señalado en la sección 140.1 literal b del Manual del Código de Ética para Profesionales de la Contabilidad, estableciendo que "el profesional contable manifiesta su respeto a través de la abstención de utilizar información confidencial obtenida como resultado de relaciones profesionales y empresariales en beneficio propio o de terceros" (IESBA, 2014, p. 19); en concordancia con lo establecido en la sección 100.5, literal (a) del referido manual en la cual se ofrece la definición de integridad como "ser franco y honesto en todas las relaciones profesionales y empresariales".

En este contexto, la integridad constituye un aspecto que el auditor debe poseer para realizar un trabajo de calidad y manifestar su respeto hacia los demás, ser un individuo fiable que permita brindar seguridad a los usuarios, evitando cometer actos de corrupción, sobornos, robos que están fuera de los estándares legales y que afectaría la credibilidad de la profesión.

Ahora bien, la integridad no es la única cualidad del auditor respetuoso, las afirmación del sujeto A1, expresan que la experiencia forma parte de las acciones que el profesional debe poseer para realizar todos los procedimientos adecuados y de este modo evitar sacar ventaja de la información suministrada, puesto que la experiencia constituye un valor fundamental para desarrollar las diferentes pruebas de una manera correcta y confiable.

Así lo demanda la sección 330.2 del Manual del Código de Ética para Profesionales de la Contabilidad (IESBA, 2014), el cual expone que existen circunstancias que ocasionan al profesional contable amenazas que impiden desempeñar sus tareas de tal manera que su diligencia y competencia profesional sean las más altas y correctas, entre ellas están, la carencia de suficiente experiencia y formación tanto práctica como teórica.

En este contexto, la experiencia coadyuva a que el auditor tome actitudes razonables que lo conduzcan al correcto desarrollo del proceso de auditoría, generando así, el respeto hacia los usuarios y la credibilidad de los resultados obtenidos. Los auditores mantienen un comportamiento fundamentado en el respeto garantizando un trabajo profesional bajo conceptos de integridad, honestidad y responsabilidad, trabajando apegado a una serie de principios morales y éticos conjuntamente con normas y leyes que determinan el correcto desarrollo de la auditoría.

Adicionalmente, los hallazgos de la investigación develan que los profesionales en actividad de auditoría cumplen con el principio de Confidencialidad establecido en el Manual del Código de Ética para Profesionales de la Contabilidad (IESBA, 2014), buscando garantizar el respeto por sus clientes y manteniendo criterios de secreto profesional al no divulgar información referente a la entidad auditada.

Contradictoriamente, la actitud de estos auditores es cuestionable, tomando en consideración que su discurso manifiesta respeto por sus clientes y por la legislación, no así, por su profesión, apartándose del principio de Comportamiento profesional exigido por el Manual del Código de Ética para Profesionales de la Contabilidad (IESBA, 2014); así como de la atención del interés público, demandado por las Normas Internacionales de Auditoría (IAASB, 2016).

\section{Confianza o Confiabilidad}

La confianza como último elemento de la confidencialidad constituye un factor esencial que la sociedad deposita en los auditores como responsables de brindar un servicio de calidad, transparente e íntegro. Los constructos teóricos que sirvieron de apoyo para el desarrollo de este componente se extrajeron de las Normas Internacionales de Auditoría (IAASB, 2016), Manual del Código de Ética para Profesionales de la Contabilidad (IESBA, 2014), (Gil y Rondón, 2016; Barrainkua, 2012; Melgarejo, 2006; Álvarez, 2002). 
La confianza constituye uno de los elementos de la confidencialidad que permite lograr que el cliente asuma una postura cómoda y abierta a la hora de suministrar la información necesaria para la realización de la auditoría, es por ello, que ésta debe estar inherente a la personalidad del profesional para facilitar dicho proceso, por lo tanto, se le preguntó a los auditores ¿Cuáles son los aspectos de su personalidad que le permite ganar la confianza a sus clientes? Las respuestas se presentan en la tabla 5.

TABLA 5

Aspectos personales de los auditores que les permiten ganar la confianza a sus clientes

\begin{tabular}{|c|c|}
\hline $\begin{array}{l}\text { Código de } \\
\text { análisis }\end{array}$ & Extracto de los Hallazgos \\
\hline A1 & Pienso que ha sido la trayectoria, la experiencia, el trabajo realizado. \\
\hline $\mathrm{A} 2$ & $\begin{array}{l}\text { Si yo quiero ganar la confianza de los clientes debo trabajar con } \\
\text { sinceridad, trabajar con honestidad, con rectitud, con responsabilidad, } \\
\text { mantener ese espiritu de confidencialidad, guardar el secreto } \\
\text { profesional, porque eso es lo que te va ayudar a ti a que el cliente te } \\
\text { recomiende. }\end{array}$ \\
\hline A3 & $\begin{array}{l}\text { El auditor tiene que generar confianza y eso se gana con el desempeño } \\
\text { profesional, la seriedad y la puntualidad. Esas cualidades permiten que } \\
\text { la información obtenida en los procesos de auditoria tiene que ser } \\
\text { manejada con mucha confidencialidad, es un patrimonio inherente del } \\
\text { auditor. }\end{array}$ \\
\hline A 4 & $\begin{array}{l}\text { Las firmas generalmente funcionan por referencias, aquí no vale que yo } \\
\text { me anuncie en la radio, en la prensa o en la televisión; más allá de la } \\
\text { personalidad, eso poco influye, está el trabajo bien hecho año tras año y } \\
\text { los clientes ven que la información está en resguardo contigo. }\end{array}$ \\
\hline A5 & $\begin{array}{l}\text { La experiencia y el trato con el cliente ayuda a conseguir más clientes o } \\
\text { ampliar tu cartera. Uno tiene que estar pendiente de ellos, visitándolos, } \\
\text { enviándoles información de todos los cambios que sacuden el país, es } \\
\text { tenerlos al dia, atenderlos a cualquier hora, es eso lo que me permite } \\
\text { ganar la confianza de los clientes. }\end{array}$ \\
\hline A 6 & $\begin{array}{l}\text { A través del trabajo que uno hace logra ser una marca personal basada, } \\
\text { por supuesto, en el conocimiento, actitud, organización, compromiso, } \\
\text { constancia. Y esa marca personal es la que permite que el cliente confie } \\
\text { en ti como contador o auditor -en nuestro caso-. Por supuesto basado en } \\
\text { una serie de principios y valores que están intrinsecos en la persona. }\end{array}$ \\
\hline
\end{tabular}

Fuente: instrumento aplicado por los investigadores, 2018.

Con base en los hallazgos presentados en la tabla 5, los auditores A1, A5 y A6 exponen que la trayectoria, la experiencia y el conocimiento son herramientas que permiten obtener la confianza de los usuarios, debido a que los mismos garantizan que el trabajo de auditoría se realice fundamentado en leyes y normas que guíen de manera correcta todo el proceso, además de brindarle al auditor la formación de un juicio profesional basado en argumentos sólidos que le ayuden a tomar decisiones razonables y acertadas en los momentos necesarios.

La sección 100.5 literal (c) del Manual del Código de Ética para Profesionales de la Contabilidad expresa que se debe manejar una competencia y diligencia profesional en la búsqueda de "mantener el conocimiento la aptitud profesional al nivel necesario para asegurar que el cliente o la entidad para la que trabaja reciben un servicio profesional competente" (IESBA, 2014).

En este contexto, poseer conocimientos y experiencia al momento de relacionarse con los clientes conlleva a que estos sientan confianza y seguridad del servicio que se le presta, además de facilitarle al profesional desenvolverse de una manera práctica y sencilla a la hora de analizar la información que se le suministra y brindar un informe congruente con la situación real de la entidad. Todo esto enmarcado en el cumplimiento del apartado 3 de la NIA 200, la cual expresa que "el objetivo del auditor es aumentar el grado de confianza de los usuarios en los estados financieros" (IAASB, 2016).

Por otra parte, el resguardo de la información es otro factor que el auditor debe considerar para obtener la confianza del cliente y los usuarios de la información financiera, así lo expresan los sujetos A2, A3 y A4, 
quienes manifiestan que mantener el secreto profesional o la confidencialidad de toda la información que se les suministra es la clave para que los usuarios confíen plenamente en los servicios que el profesional brinda.

$\mathrm{Al}$ respecto, la sección 140.1 del Manual del Código de ética para Profesionales de la Contabilidad (IESBA, 2014) expone que el auditor debe abstenerse de divulgar información confidencial obtenida de relaciones profesionales y empresariales; sin embargo, el profesional también debe velar por el interés público y garantizar que todo el trabajo de auditoría se realizó de manera correcta y transparente, así lo afirma Álvarez (2002, p. 161) quien expone que el contador es depositario de la confianza, da fe pública cuando con su firma y número de colegiatura profesional suscribe un documento que certifique sobre determinados hechos económicos.

Con base en estos hallazgos podría afirmarse que los auditores entrevistados poseen una serie de características en su personalidad que generan confianza a los usuarios y sus clientes, conformada por los conocimientos, experiencia y el resguardo de la información.

Aunado a esto, la práctica de los principios éticos y morales que le aportan al profesional a un comportamiento culto y educado son considerados por los auditores A2, A3 y A6, quienes establecen en su discurso que los mismos deben ser intrínsecos al auditor, tales como: responsabilidad, honestidad, sinceridad y puntualidad; que en conjunto contribuyen a generar la confianza que los clientes necesitan. Ajustándose de esta manera a los preceptos dictados por la NIA 200 (IAASB, 2016), estableciendo que el auditor está sujeto a los requerimientos de ética aplicables a los encargos de auditoría de estados financieros.

La referida normativa en el apartado 1 establece las responsabilidades globales que tiene el auditor independiente cuando realiza una auditoría de estados financieros, dentro de las cuales resalta que una auditoría desarrollada bajo principios éticos y morales fundamenta la confianza de los clientes, debido a que son conceptos que exteriorizan rectitud e integridad en el profesional contable, además de ser preceptos universales que controlan el comportamiento del hombre en la sociedad.

Adicionalmente, el auditor A4 expresó que el prestigio obtenido a lo largo de su carrera profesional, son pilares para ganar la confianza de sus clientes, debido a que esto les brinda la oportunidad de venderse de manera rápida y positiva en un mercado competitivo. El auditor $\mathrm{A} 6$ coincide con esta opinión al manifestar que durante el trabajo que se realiza, el profesional forma su propia marca personal, basada en una serie de características como organización, actitud, compromiso y constancia.

Alonso (2014, p. 2) señala que las marcas personales deben ser elaboradas y transmitidas con el objetivo de diferenciarse y poder conseguir el mayor éxito posible en las relaciones sociales y personales. Argumentado en lo expresado por los auditores se puede afirmar, que crear una marca personal genera el factor confianza de los clientes, ya que los profesionales resaltan su éxito en el ámbito contable y a su vez los usuarios se interesan en confiar el trabajo en personas reconocidas y con prestigio.

Una vez interpretados los fundamentos conceptuales expuestos podría afirmarse que los auditores develaron un conjunto de aspectos que generan confianza: 1) parten de la premisa que poseer conocimientos y experiencias brinda opiniones con fundamentos razonables; 2) salvaguarda de la información suministrada amparada bajo el principio de confidencialidad; 3) mantenimiento de un comportamiento profesional acogido a altos niveles de ética que además contribuye a garantizar que la auditoría se desarrolla de una manera transparente; y 4) estructura una marca personal enfocados en el éxito y el reconocimiento de sus clientes.

\section{CONSIDERACIONES FINALES}

Con base en los argumentos expuestos por los auditores entrevistados se puede considerar que la independencia representa un aspecto fundamental para garantizar la confidencialidad, evaluando el mantenimiento de un comportamiento estrictamente profesional con sus clientes, a fin de evitar que los factores internos o externos interfieran en la objetividad de su trabajo. Aunado a esto, los conocimientos y las 
experiencias adquiridas son aspectos aplicados para garantizar la autonomía, y brindan un juicio profesional sólido que les permite a los auditores emitir opiniones razonables de conformidad con la exigencia del entorno.

En la actividad profesional de auditoría es fundamental establecer los acuerdos y lineamientos entre el auditor y su cliente a través de un contrato, de modo tal, que la independencia no esté restringida por causales que limiten el alcance del trabajo impuestas por la entidad auditada. No obstante, los auditores deben reflexionar sobre la aplicación del escepticismo profesional para garantizar la autonomía, tomando en cuenta que su desarrollo podría permitirles la afluencia de una mentalidad cuestionante de toda la información que presenta la entidad, lo cual conduciría a la aplicación de procedimientos de auditoría que confirmen los riesgos evaluados, y por tanto, den credibilidad al trabajo profesional.

El respeto por los demás representa el segundo elemento de la confidencialidad presente en el ejercicio profesional de los auditores entrevistados, y busca fomentar el correcto comportamiento que el auditor exterioriza ante los usuarios. Esta cualidad se puede describir como un conjunto de valores impregnados en el profesional que lo conducen a tomar acciones honestas, íntegras consigo mismo, con los usuarios y con la profesión, garantizando la transparencia del proceso de auditoría para brindar resultados confiables.

Para mantener el respeto, los auditores no deben sacar ventaja de la información obtenida para beneficios propios o de terceros, reduciendo la posibilidad de amparar actividades fraudulentas con su labor, cuyas consecuencias afecten la credibilidad de su trabajo. Igualmente, los auditores mantienen un comportamiento firme, alejado de convertirse en cómplices de sus clientes, considerando evitar sanciones personales de tipo penales o administrativas de acuerdo con el cumplimiento legislativo.

La responsabilidad representa un valor fundamental en el desarrollo del respeto, tomando en cuenta que esta permite establecer niveles óptimos de compromiso, entrega y dedicación en la ejecución de un trabajo, direccionándolo a brindar resultados basados en la objetividad y seriedad. Sin embargo, los auditores entrevistados, aun cuando exteriorizaron en su discurso diferentes valores personales que los incita a mantener un respeto por los demás, no consideran la atención del interés público como factor primordial de su profesión, por tanto, se alejan del cumplimiento normativo establecido sobre su actividad.

Por otra parte, la confianza es el último elemento de la confidencialidad y se describe como el factor esencial que la sociedad ha depositado en los auditores como responsables de brindar un servicio de calidad, se manifiesta a través de un conjunto de cualidades que el profesional posee y buscan que los clientes se sientan cómodos al momento de suministrar la información y permitan que el proceso de la auditoría se ajuste al tiempo establecido, a fin de atender criterios de celeridad y razonabilidad.

Estas cualidades han permitido que la confianza se afiance en mantener un comportamiento confidencial que asegure el resguardo de la información; garantizar los conocimientos y la experiencia suficiente para brindar calidad en el servicio, así como profesionalismo y seriedad en la auditoría; trabajar bajo conceptos de honestidad y puntualidad que garanticen un trabajo eficaz y transparente; y conseguir el reconocimiento y prestigio fundamentado en crear una marca personal que los conlleve al éxito de su labor realizada.

\section{Referencias}

Alonso, A. (2014. La importancia de la marca personal. Universidad de León España. Consultado el 27 de junio de 2018 en: https://buleria.unileon.es/bitstream/handle/10612/4143/70893355H_GADE_Septiembre14\%2 $0 \% 281 \% 29$.pdf?sequence $=1$

Álvarez, M. (2002). El contador público y su responsabilidad social. Contaduría, 41. Consultado el 23 de enero de 2018 en: http://bibliotecadigital.udea.edu.co/bitstream/10495/4945/1/\%C3\%81lvarezM_2002_ContadorP \%C3\%BAblicoResponsabilidadSocial.pdf

Arias, F. (2012). El proyecto de investigación. Introducción a la metodología cientifica. Caracas: Editorial Espíteme. 
Asamblea Nacional de la República Bolivariana de Venezuela. (1999). Constitución de la República Bolivariana de Venezuela. Caracas.

Asamblea Nacional de la República Bolivariana de Venezuela. (2012). Ley Orgánica contra la delincuencia organizada y financiamiento al terrorismo. Caracas, Venezuela.

Asociación Médica Mundial - AMM (2015). Manual de Ética Médica, 5a ed. Consultado el 27 de diciembre de 2017 en https://www.wma.net/es/que-hacemos/educacion/manual-de-etica-medica/

Barrainkua, I. (2012). Hacia una ética universal para la profesión contable: análisis de las restricciones culturales y socioeconómicas en la convergencia del Código de Ética Internacional Universidad del País Vasco (Europa). Consultado el 12 de octubre de 2017 en: https://addi.ehu.es/bitstream/handle/101810/13964/TFMBarraink ua.pdf?sequence $=1 \&$ isallowed $=\mathrm{y}$

Campo, M. y Tejero, J. (2005). Psicopedia hoy. La intencionalidad del psicólogo, 7(2). Consultado el 28 de diciembre de 2017 en: http://psicopediahoy.com/intencionalidad-del-psicologo/.

Diccionario de la Real Academia Española - RAE. (2014). Consultado el 20 de diciembre de 2017 en: http://dle.rae.es

Gil, M. y Rondón, K. (2016). Confianza generada por la actuación del Contador Público independiente ante las Instituciones Financieras del Municipio Valera, Estado Trujillo. Trujillo Venezuela.

International Auditing and Assurance Standars Board - IAASB. (2016). Norma Internacional de Auditoria № 240, Responsabilidades del Auditor en la auditoría de estados financieros con respecto al fraude. Londres, Inglaterra. Traducción del Instituto Mexicano de Contadores.

International Auditing and Assurance Standars Board - IAASB. (2016). Norma Internacional de Auditoria No 250, Consideración de las disposiciones legales y reglamentarias en la auditoría de estados financieros. Londres, Inglaterra. Traducción del Instituto Mexicano de Contadores.

International Auditing and Assurance Standars Board - IAASB. (2016). Norma Internacional de Auditoria No 450, Evaluación de las Incorrecciones identificadas durante la realización de la Auditoría. Londres, Inglaterra. Traducción del Instituto Mexicano de Contadores

International Auditing and Assurance Standars Board - IAASB. (2016). Norma Internacional de Control de Calidad (NICC) 1 Control de Calidad en las firmas de auditorías que realizan auditorías y revisiones de Estados Financieros así como otros encargos que proporcionan un grado de seguridad y servicios relacionados. Londres.

International Auditing and Assurance Standars Board - IAASB. (2016). Norma Internacional de Auditoria № 200, Objetivos y principios generales que gobiernan una auditoría de estados financieros. Londres.

International Auditing and Assurance Standars Board - IAASB. (2016). Norma Internacional de Auditoria № 210, Acuerdos de los Términos del Encargo de Auditoría. Londres.

International Auditing and Assurance Standars Board - IAASB. (2016). Norma Internacional de Auditoria № 220, Control de Calidad de la Auditoría de Estados Financieros. Londres.

International Auditing and Assurance Standars Board - IAASB. (2016). Norma Internacional de Auditoria No 260, Comunicación con los responsables del gobierno de la entidad. Londres.

International Ethics Standards Board for Accountants - IESBA. (2014). Manual del Código de Ética para profesionales de la Contabilidad. Londres.

Melgarejo, R. (2006). Las auditorias confirman la confiabilidad de la información financiera de las empresas. Consultado el 24 de enero de 2018 en: https://www.ccpm.org.mx/avisos/31\%20JL\%2006\%20\%20COM\%20AUDITOR IA.pdf

Monje, C. (2011). Metodología de la Investigación Cuantitativa y Cualitativa. Guía Didáctica. Universidad Surcolombiana. Neiva, Colombia. Consultado el 22 de febrero de 2018 en: https://www.uv.mx/rmipe/files/20 17/02/Guia-didactica-metodologia-de-la-investigacion.pdf

Piaget, J. (1960). La Nueva Educación Moral. Buenos Aires: Editorial Losada.

Presidencia de la República Bolivariana de Venezuela (2014). Decreto con Rango Valor y Fuerza de Ley del Código Orgánico Tributario. Gaceta Oficial No 6152 Extraordinario. Caracas. 
Ramírez, L., Arcila, A., Buriticá, L. \& Castrillón J. (2004. Paradigmas y Modelos de Investigación. Guía didáctica y Módulo, 2a ed. Medellín, Colombia. Consultado el 13 de marzo de 2018 en: http://virtual.funlam.edu.co/repo sitorio/sites/default/files/repositorioarchivos/2011/02/0008paradigmasymodelos.771.pdf

Slosse, C. (2002. Aportes de la auditoría a las expectativas y necesidades de los usuarios de información contable. Boletin de Lecturas Sociales y Económicas UCA FCSE, 2(5). Consultado el 22 de enero de 2018 en: http://200. 16.86.50/digital/33/revistas/blse/slosse1-1.pdf

Viloria, N. (2009). La importancia del concepto de independencia para la auditoría. Actualidad Contable FACES, 12(18), 115-124. Consultado el 29 de diciembre de 2017 en: http://www.saber.ula.ve/bitstream/handle/1234 56789/29616/articulo9.pdf? sequence $=1$

\section{Notas}

* Artículo de reflexión.

\section{Licencia Creative Commons CC BY 4.0}

Para citar este artículo: Ruza, W., Valderrama, Y., y Leal. E. (2019). Elementos de la confidencialidad en el ejercicio profesional del auditor. Cuadernos de Contabilidad, 20(49). DOI: https://doi.org/10.11144/Jave riana.cc20-49.ecep 